\title{
Vitamin D and atopy and asthma phenotypes in children: a longitudinal cohort study
}

\author{
E.M. Hollams*,\#,§, P.H. Hart*,\#,\$, B.J. Holt*\#, M. Serralha*\#, F. Parsons*,\#, \\ N.H. de Klerk* ${ }^{\star}$, , G. Zhang ${ }^{\star}$, P.D. Sly ${ }^{+}$and P.G. Holt*
}

ABSTRACT: Vitamin D has been linked in some studies with atopy- and asthma-associated phenotypes in children with established disease, but its role in disease inception at the community level is less clear. The aim of the present study was to investigate associations between vitamin $D$ status and biological signatures indicative of allergy and asthma development in children aged 6 and 14 years in Perth, WA, Australia (latitude $32^{\circ} \mathrm{S}$ ).

Serum vitamin D was assayed in 989 6-yr-olds and 1,380 14-yr-olds from an unselected community birth cohort; 689 subjects were assessed at both ages. Vitamin D levels were assessed as a risk modifier for respiratory and allergic outcomes at both ages, using previously ascertained phenotypic data. The predictive value of vitamin D levels at age 6 yrs for development of clinical phenotypes at age 14 yrs was also examined.

Serum vitamin D levels in children of both ages were negatively associated with concurrent allergic phenotypes; sex stratification revealed that this association was restricted mainly to males. Furthermore, vitamin D levels at age 6 yrs were significant predictors of subsequent atopy/ asthma-associated phenotypes at age 14 yrs.

In an unselected community setting, children (particularly males) with inadequate vitamin $\mathrm{D}$ are at increased risk of developing atopy, and subsequently bronchial hyperresponsiveness (BHR) and asthma. In a large unselected cohort, males with inadequate vitamin D at 6 and 14 yrs of age had increased atopy and BHR. Low vitamin D at age 6 yrs was a predictor of atopy and asthma at 14 yrs of age.

KEYWORDS: Asthma, atopy, bronchial hyperresponsiveness, male bias, Raine Study, vitamin D

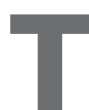
here is increasing awareness of the importance of vitamin $\mathrm{D}$ for the maintenance of general immune and respiratory health $[1$,

2]. Humans obtain $>80 \%$ of their vitamin D via exposure to the ultraviolet $\mathrm{B}$ components of sunlight, consistent with findings of significant seasonal variation in the circulating levels of 25-hydroxyvitamin D3 in individuals living in nonequatorial locations. The levels of vitamin D required may vary for different biological needs but $>75 \mathrm{nmol} \cdot \mathrm{L}^{-1}\left(30 \mathrm{ng} \cdot \mathrm{mL}^{-1}\right)$ is currently considered optimal, whilst $50-75 \mathrm{nmol} \cdot \mathrm{L}^{-1}$ may be insufficient and $<50 \mathrm{nmol} \cdot \mathrm{L}^{-1}$ deficient [3-5]

A relationship between inadequate vitamin D and development and severity of allergy and asthma has been proposed [2-4, 6, 7]. In adults, reduced vitamin D levels associate with impaired lung function, increased airway hyperresponsiveness and reduced responsiveness to glucocorticoids $[1,8]$. Furthermore, vitamin $\mathrm{D}$ has been used as a therapy to treat glucocorticoid resistance in some asthmatic patients $[9,10]$, and an association has recently been reported in asthmatic children between serum vitamin D levels and increased glucocorticoid use [5]. Data from rodent models suggest that vitamin D can control sensitisation to allergens by both regulation of dendritic cell development [11] and induction of interleukin (IL)-10-producing CD4+ CD25+ regulatory T-cells $[10,12]$.

Vitamin D status may affect the development of allergies and asthma earlier in life [13]. In a large study of cord blood mononuclear cells from children of parents with allergic disease or
AFFILIATIONS

*Telethon Institute for Child Health Research,

\# Centre for Child Health Research,

"School of Paediatrics and Child Health, Faculty of Medicine, Dentistry and Health Services, University of Western Australia, Perth, WA, +Queensland Children's Medical Research Institute, University of Queensland, Royal Children's Hospital, Brisbane, QLD, Australia.

${ }^{\S}$ These authors contributed equally.

CORRESPONDENCE

P.G. Holt

Telethon Institute for Child Health

100 Roberts Road

Subiaco WA 6008

Australia

E-mail: patrick@ichr.uwa.edu.au

Received:

Feb 162011

Accepted after revision:

April 282011

First published online:

May 122011 
asthma [14], the strongest correlate of responsiveness to innate and adaptive immune stimuli was season of birth, which may reflect vitamin D status. High maternal intake of vitamin D during pregnancy or by infants in the first year of life has been associated both negatively $[15,16]$ and positively $[17,18]$ with wheeze or asthma in their children.

Previous studies of vitamin D levels and expression of allergy and asthma phenotypes have concentrated on children already diagnosed with asthma. For example, low vitamin $\mathrm{D}$ was significantly associated with markers of allergy and asthma in asthmatic Costa Rican children between the ages of 6 and 14 yrs [19] but not asthmatic children from North American cities [20]. In a different study of 100 asthmatic children [6], vitamin D levels inversely correlated with immunoglobulin (Ig)E levels and sensitisation to aeroallergens. These reports highlight the need for further analysis of the links between vitamin D status, and allergy and asthma in different populations. Furthermore, the possibility that vitamin D may modulate the development of wheezing-related phenotypes prior to asthma diagnosis must be considered. In this longitudinal, community-based study of children conducted in Perth, WA, Australia (latitude $32^{\circ} \mathrm{S}$ ), associations were sought between vitamin D status (serum 25hydroxyvitamin D levels) determined at 6 and 14 yrs of age, and biological signatures indicative of allergy and asthma development. This study was able to detect links between vitamin D levels and the progression of children into a phenotype characterised by atopy, bronchial hyperresponsiveness (BHR) and asthma.

\section{METHODS}

\section{Study subjects}

Subjects were from the West Australian Pregnancy Cohort (Raine Study), which is a longitudinal birth cohort; mothers were not selected on any criteria other than having enrolled for antenatal care at the main local tertiary maternity hospital [21]. Analyses were based on clinical and immunological data collected at the age 6 yrs and age 14 yrs follow-up visits. The study was approved by the Princess Margaret Hospital Ethics Committee (Perth, WA, Australia) with consent given by parents and subjects.

\section{Vitamin D levels}

Vitamin D, which is stable in long-term storage [22], was measured in thawed serum cryobanked at age 6 yrs (989 subjects) and 14 yrs (1,380 subjects). Serum 25-hydroxyvitamin $\mathrm{D}$ levels were measured using the enzyme immunoassay kit from Immunodiagnostic Systems Ltd (Scottsdale, AZ, USA). 12 subjects at each age also had 25-hydroxyvitamin D3 measured by isotope-dilution liquid chromatography-tandem mass spectrometry by RMIT Drug Discovery Technologies (Melbourne, VIC, Australia) according to published methodology [23]. As noted in figure E1 (online supplementary material), correlation between the methods at age 14 yrs was strong $\left(r^{2}=0.933\right)$, whereas the immunoassay method appeared to overestimate the vitamin D levels at age 6 yrs, suggesting the presence in serum of vitamin D metabolites that cross-react with the immunoassay antibodies. Notwithstanding this, as shown herein, relationships between estimated vitamin D levels and clinical phenotypes were comparable at both ages.

\section{Clinical and immunological phenotyping at ages 14 and 6 yrs}

Current respiratory and allergic conditions

Current asthma was defined as wheeze plus use of any asthma medication in the last 12 months, in children with a prior doctor diagnosis of asthma. Current rhinoconjunctivitis was assessed via parental response to a standardised questionnaire regarding the child's symptoms (runny, blocked or itchy nose in the presence of runny or itchy eyes) over the preceding 12 months.

Total and specific IgE were measured by ImmunoCap (Phadia AB, Uppsala, Sweden) as described previously [24] and in the online supplementary material. Subjects were considered atopic if they had any measured specific IgE $\geqslant 0.35 \mathrm{kU} \cdot \mathrm{L}^{-1}$ and/or total $\operatorname{IgE} \geqslant 300 \mathrm{kU} \cdot \mathrm{L}^{-1}$ for age 14 yrs or total $\mathrm{IgE} \geqslant 100 \mathrm{kU} \cdot \mathrm{L}^{-1}$ for age 6 yrs.

\section{Respiratory assessment}

Lung function was assessed by spirometry and BHR was assessed by methacholine challenge, as detailed previously $[24,25]$ and in the online supplementary material.

\section{Measurement of cellular markers at age 14 yrs}

Haematological profiles were recorded from fresh samples on the day of blood collection, with the remainder cryopreserved as viable peripheral blood mononuclear cells (PBMCs) [24]. PBMC samples were thawed and cultured either with house dust mite (HDM) allergen, lipopolysaccharide (LPS) or polyinosinic: polycytidylic acid (poly(I:C)); cytokine responses were subsequently assayed in culture supernatants by time-resolved fluorometry [24].

\section{Statistical analyses}

See the online supplementary material for additional details of the statistical analyses used. Prevalence of respiratory and allergic outcomes at age 14 yrs was compared between subjects sufficient for vitamin D at age 14 yrs (vitamin $\mathrm{D}>75 \mathrm{nmol} \cdot \mathrm{L}^{-1}$ ) and remaining subjects using Chi-squared testing. $\log _{10^{-}}$ transformed actual vitamin $\mathrm{D}$ was used in univariate linear regression with continuous variables and in univariate logistic regression to predict binary clinical outcomes. A sinusoidal model incorporating month of blood collection was fitted to the actual vitamin $\mathrm{D}$ concentration for each subject to calculate “de-seasonalised vitamin D" [26], which was $\log _{10}$-transformed and entered into regression analyses as for actual vitamin D. Bivariate relationships between vitamin D and immunological variables were assessed using Spearman's correlation.

\section{RESULTS}

\section{Vitamin D status at age 14 yrs}

Levels of vitamin D were initially measured in serum samples collected at 14 yrs of age. Blood collection from these subjects took place over 3 yrs approximating their 14th birthdays, and figure 1a shows the mean vitamin $\mathrm{D}$ levels per collection day over this period. Levels were lowest in mid-Winter (July) and in Spring, then rose to peak around mid-Summer. Overlaying plots of mean HDM-specific IgE and serum vitamin D levels per collection month (fig. 1b) revealed an apparent inverse correlation between these parameters (Spearman correlation: $r=$ -0.092, $\mathrm{p}=0.001)$. This and related observations were explored in more detail in the analyses described herein. 

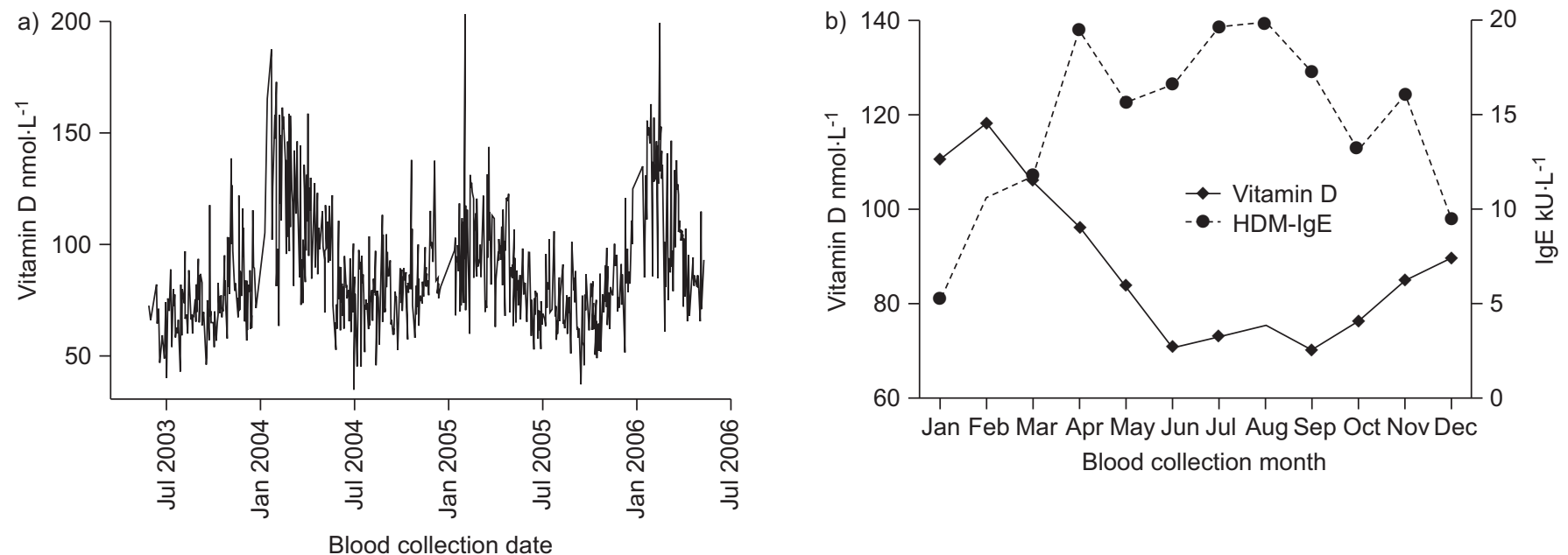

FIGURE 1. Seasonal variation of serum vitamin D levels. Vitamin D was measured by enzyme immunoassay from serum, which was collected from $1,38014-y r-0 l d s$ over a 3-yr period. a) Mean vitamin D levels measured for each day of blood collection are shown. b) Mean vitamin D levels for blood collection months combined over the 3-yr period are shown; mean house dust mite (HDM) allergen immunoglobulin $(\mathrm{Ig})$ E titres from these subjects were similarly calculated and presented.

At age 14 yrs, only $59.3 \%$ of the 1,380 subjects had what is currently considered sufficient levels of vitamin $\mathrm{D}\left(>75 \mathrm{nmol} \cdot \mathrm{L}^{-1}\right)$; $4.4 \%$ could be considered vitamin D-deficient $\left(<50 \mathrm{nmol} \cdot \mathrm{L}^{-1}\right)$ while $36.3 \%$ of subjects had insufficient vitamin $\mathrm{D}\left(50-75 \mathrm{nmol} \cdot \mathrm{L}^{-1}\right)$ (see online supplementary table E1). Vitamin D deficiency was most common in subjects whose blood was collected in Winter (34 (9.4\%) out of 362 subjects) followed by Spring (22 (5.5\%) out of 399 subjects). Only five out of 391 subjects with blood collected in Autumn were vitamin D deficient and none of the subjects bled in summer were deficient.

Preliminary Chi-squared analyses were performed to examine the relationships between vitamin D status and the asthma- and atopy-associated phenotypes previously ascertained at age 14 yrs [24]. As illustrated in online supplementary table E2, subjects without sufficient vitamin D at 14 yrs of age had a significantly higher prevalence of BHR and atopy, in particular, HDM sensitisation, which is the strongest marker of the atopic phenotype in this population [24]. There was also a trend for increased prevalence of rhinoconjunctivitis. Several conditions were more prevalent in males than females, including atopy (65.2 versus $54.4 \%$; $\mathrm{p}<0.001$ ), HDM sensitisation (43.6 versus $34.4 \% ; \mathrm{p}<0.001)$ and poor lung function (10.0 versus $4.8 \%$; $\mathrm{p}<0.001$ ). Inverse relationships between vitamin D status and prevalence of clinical conditions were seen only amongst males; compared with males with sufficient vitamin $\mathrm{D}$, those without sufficient vitamin D had an increased frequency of BHR (19.6 versus $13.3 \%$; $=0.031)$, atopy $(72.2$ versus $61.1 \% ; p=0.003)$ and HDM sensitisation (50.2 versus $39.8 \%$; $\mathrm{p}=0.007$ ). There were similar trends for asthma (13.5 versus $9.4 \% ; \mathrm{p}=0.094)$ and poor lung function (forced expiratory volume in $1 \mathrm{~s}$ (FEV1)/forced vital capacity $(\mathrm{FVC})$ ratio $<80 \%)(12.5$ versus $8.5 \%$; $\mathrm{p}=0.087)$.

\section{Associations between current vitamin D level, and respiratory and allergic phenotypes at age 14 yrs}

Our previous studies on this cohort at age 14 yrs demonstrated strong associations between atopy and a range of asthma-related phenotypes [24], and accordingly, relationships were examined between these outcomes and vitamin D levels. We performed initial multivariate regression analyses adjusting for the potential confounders sex and collection month; both these variables showed significant association with one or more outcomes (online supplementary table E3) and accordingly, follow-up analyses included sex stratification and (where appropriate) deseasonalisation of vitamin $\mathrm{D}$ data. Univariate logistic regression analyses (table 1) demonstrated that low serum vitamin D levels

\section{TABLE 1 Univariate logistic regression with vitamin D for respiratory and allergic conditions: age 14 yrs}

\begin{tabular}{|c|c|c|c|c|c|c|c|c|c|}
\hline \multirow{2}{*}{$\begin{array}{l}\text { Outcomes at age } \\
14 \mathrm{yrs}\end{array}$} & \multicolumn{3}{|c|}{ Whole population } & \multicolumn{3}{|c|}{ Males } & \multicolumn{3}{|c|}{ Females } \\
\hline & $\begin{array}{c}\text { Subjects } \\
n / N\end{array}$ & OR $(95 \% \mathrm{Cl})$ & $\mathrm{p}$-value & $\begin{array}{c}\text { Subjects } \\
n / N\end{array}$ & OR $(95 \% \mathrm{Cl})$ & $p$-value & $\begin{array}{c}\text { Subjects } \\
n / N\end{array}$ & OR (95\% Cl) & $p$-value \\
\hline BHR & 236/1286 & $0.35(0.13-0.95)$ & 0.039 & $104 / 666$ & $0.33(0.07-1.48)$ & 0.148 & $132 / 620$ & $0.44(0.11-1.69)$ & 0.232 \\
\hline Atopy & $827 / 1379$ & $0.49(0.23-1.06)$ & 0.071 & $465 / 713$ & $0.22(0.07-0.67)$ & 0.008 & $362 / 666$ & $0.79(0.27-2.34)$ & 0.672 \\
\hline
\end{tabular}

Actual vitamin $\mathrm{D}$ at age $14 \mathrm{yrs}$ (in $\mathrm{nmol} \cdot \mathrm{L}^{-1}$ ) was $\log _{10}$-transformed and included in univariate logistic regression analyses for outcomes at age 14 yrs. Forced expiratory volume in $1 \mathrm{~s} /$ forced vital capacity ratio $<80 \%$ was the criterion used to define poor lung function at age $14 \mathrm{yrs}$. $\mathrm{n}$ : total subjects in regression; $\mathrm{N}$ : subjects in regression with outcome; BHR: bronchial hyperresponsiveness; HDM: house dust mite 
TABLE 2 Linear regression between vitamin D and continuous respiratory and allergic measures at age 14 yrs

\begin{tabular}{|c|c|c|c|c|c|c|c|c|c|c|c|c|}
\hline \multirow{2}{*}{$\begin{array}{l}\text { Variable at age } \\
14 \text { yrs }\end{array}$} & \multicolumn{4}{|c|}{ Whole population } & \multicolumn{4}{|c|}{ Males } & \multicolumn{4}{|c|}{ Females } \\
\hline & Subjects & $\beta \pm S E$ & $\mathbf{t}$ & $\mathrm{p}$-value & Subjects & $\beta \pm \mathrm{SE}$ & $\mathbf{t}$ & $p$-value & Subjects & $\beta \pm S E$ & $t$ & $p$-value \\
\hline $\begin{array}{l}\text { BHR-dose } \\
\text { slope }\end{array}$ & 1271 & $-0.069 \pm 0.009$ & -2.45 & 0.014 & 657 & $-0.060 \pm 0.014$ & -1.53 & 0.127 & 614 & $-0.059 \pm 0.013$ & -1.46 & 0.145 \\
\hline HDM IgE & 1379 & $-0.073 \pm 0.003$ & -2.71 & 0.007 & 713 & $-0.098 \pm 0.004$ & -2.63 & 0.009 & 666 & $-0.065 \pm 0.004$ & -1.69 & 0.092 \\
\hline
\end{tabular}

All variables except for bronchial hyperresponsiveness (BHR)-dose slope were $\log _{10}$-transformed. Vitamin $\mathrm{D}$ was measured in $\mathrm{nmol} \cdot \mathrm{L}^{1}$ and immunoglobulin $(\mathrm{Ig}) \mathrm{E}$ was measured in kilounits per litre. $\beta$ : standardised correlation coefficient; t: $\beta$ divided by SE; HDM: house dust mite.

were associated with an increased risk of BHR and atopic sensitisation, particularly in males; furthermore, this association extended to the intensity of these clinical phenotypes, as demonstrated by linear regression analyses (table 2). Vitamin D level at age 14 yrs was not associated with risk for asthma $(p=0.306)$, rhinoconjunctivitis $(p=0.501)$, poor lung function $(p=0.540)$ or exercise-induced wheeze $(p=0.555)$ in univariate logistic regressions within the whole population, or in single-sex analyses (not shown). There was likewise no association found between FEV1/FVC and vitamin D level at age 14 yrs by linear regression (not shown).

Some of the clinical outcomes of interest in these 14-yr-olds, such as asthma and rhinoconjunctivitis, were defined by symptoms over the 12 months prior to assessment, while other outcomes, such as atopic status and BHR, reflect the results of tests performed on the day of assessment. Given that serum vitamin D status is strongly related to the date of sample collection, we repeated these analyses employing de-seasonalised vitamin D data. Comparable relationships (including the samesex stratification) were observed (online supplementary tables E4 and E5).

We examined more closely how vitamin D related to clinical conditions by looking at predicted probabilities of outcomes amongst subjects stratified by sex and vitamin D level. Males and females were separately divided into ascending quartiles based on serum vitamin D concentration, and mean predicted probabilities for atopy were calculated by logistic regression. Figure 2 shows that the probability of atopy amongst males was highest in quartile 1 and decreased as vitamin D levels increased, whereas the risk for females remained similar across the quartiles.

\section{Associations between current vitamin $D$ level and clinical phenotypes at age 6 yrs}

In light of these findings, we analysed serum samples collected earlier at the 6-yr follow-up visit (online supplementary table E1). We observed fluctuations in serum vitamin D with season of collection (not shown), similar to those observed at age 14 yrs. There was a significant correlation between vitamin $\mathrm{D}$ levels at the two ages using unadjusted vitamin $\mathrm{D}(\mathrm{r}=0.442, \mathrm{p} \leqslant 0.0001)$ or de-seasonalised vitamin $\mathrm{D}(\mathrm{r}=0.454, \mathrm{p} \leqslant 0.0001)$. Crosssectional analyses of the relationships between vitamin $\mathrm{D}$ levels and clinical phenotypes at age 6 yrs were carried out as for age
14 yrs, with the exception that BHR data at age 6 yrs was collected in only a subset of the cohort $(n=354)$ and analysed only as a binary measure.

Univariate logistic regression (table 3) and linear regression analyses (table 4) indicated inverse associations between (unadjusted) serum vitamin D, and expression of BHR and sensitisation, which were significant at age $6 \mathrm{yrs}$, albeit weaker than those observed at age 14 yrs. Notably, the stronger effects observed in males at age 14 yrs were also found for 6-yr-old males. Likewise, vitamin D level at age 6 yrs was not associated in the whole population with risk for asthma $(p=0.506)$, rhinoconjunctivitis $(\mathrm{p}=0.311)$, poor lung function (FEV1/FVC $<80 \% ; \mathrm{p}=0.601)$ or exercise-induced wheeze $(\mathrm{p}=0.118)$. A marginal inverse relationship at age 6 yrs between vitamin D and exercise-induced wheeze was seen amongst males (OR $0.143 ; p=0.057)$ but not females $(p=0.775)$. No association was found between FEV1/FVC and vitamin D by linear regression

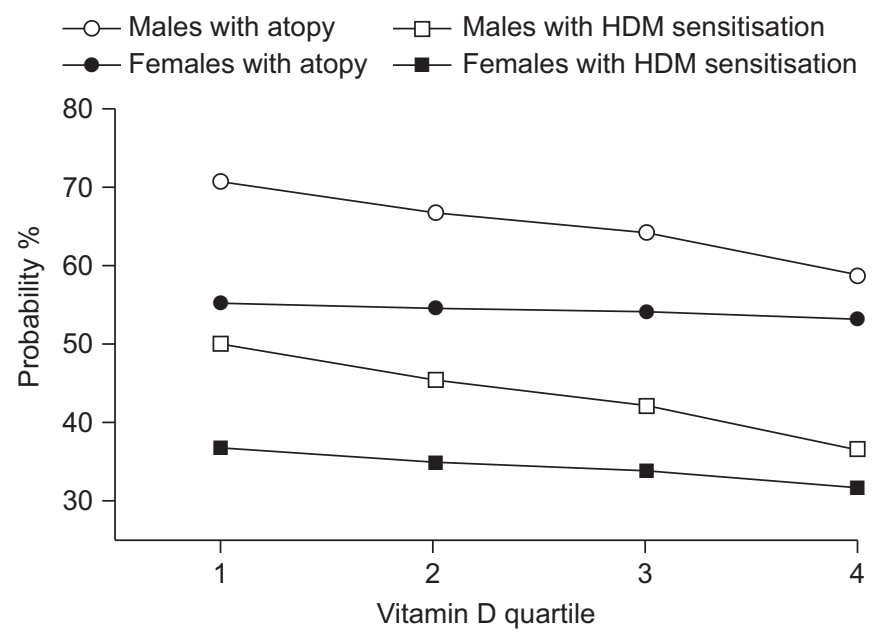

FIGURE 2. Probability of atopic sensitisation decreases as vitamin D increases in males only. Males and females were separately divided into ascending quartiles by vitamin $\mathrm{D}$ level at age $14 \mathrm{yrs}$. Predicted probabilities of atopy or house dust mite (HDM) sensitisation were calculated separately for male and female subjects by univariate logistic regression with actual vitamin D levels, and mean predicted probabilities for each quartile are shown. 
TABLE 3 Univariate logistic regression with vitamin D for respiratory and allergic conditions: age 6 yrs

\begin{tabular}{|c|c|c|c|c|c|c|c|c|c|}
\hline \multirow{2}{*}{$\begin{array}{l}\text { Outcomes } \\
\text { at age } 6 \text { yrs }\end{array}$} & \multicolumn{3}{|c|}{ Whole population } & \multicolumn{3}{|c|}{ Males } & \multicolumn{3}{|c|}{ Females } \\
\hline & Subjects $n / N$ & OR (95\% Cl) & $p$-value & Subjects $n / N$ & OR (95\% Cl) & $p$-value & Subjects $n / N$ & OR $(95 \% \mathrm{Cl})$ & $\mathrm{p}$-value \\
\hline BHR & $184 / 354$ & $0.17(0.04-0.81)$ & 0.026 & $88 / 185$ & $0.15(0.02-1.15)$ & 0.067 & $96 / 169$ & $0.30(0.03-3.37)$ & 0.327 \\
\hline Atopy & $525 / 989$ & $0.79(0.32-1.98)$ & 0.620 & $309 / 554$ & $0.40(0.12-1.38)$ & 0.147 & $216 / 435$ & $1.59(0.40-6.26)$ & 0.507 \\
\hline HDM sensitisation & 237/989 & $0.35(0.12-1.01)$ & 0.053 & $152 / 554$ & $0.24(0.06-0.99)$ & 0.048 & $85 / 435$ & $0.44(0.08-2.30)$ & 0.329 \\
\hline
\end{tabular}

Actual vitamin $\mathrm{D}$ at age $6 \mathrm{yrs}$ (in $\mathrm{nmol} \cdot \mathrm{L}^{-1}$ ) was $\log _{10}$-transformed and included in univariate logistic regression analyses for outcomes at age $6 \mathrm{yrs}$. $\mathrm{n}$ : total subjects in regression; $\mathrm{N}$ : subjects in regression with outcome; BHR: bronchial hyperresponsiveness; HDM: house dust mite.

(not shown). Similar associations were again observed employing de-seasonalised vitamin D data (online supplementary tables E6 and E7).

\section{Vitamin D levels at age 6 yrs as a predictor of subsequent clinical phenotypes at 14 yrs of age}

Of the 989 cohort members assessed at age 6 yrs, 693 subjects were part of the 14-yr follow-up, and we performed longitudinal analyses on this subgroup. We determined by Chisquared analysis that there were no significant biases due to the loss to follow-up of 307 6-yr-old subjects. De-seasonalised vitamin D levels at age 6 yrs were used in logistic regression to predict clinical outcomes at 14 yrs of age. As shown in table 5, in the overall population, low vitamin D levels at age 6 yrs were associated with an increased risk of atopy but not BHR at age 14 yrs. In addition, predictive associations were evident between vitamin $\mathrm{D}$ at age 6 yrs and subsequent asthma, and, to a lesser extent, rhinoconjunctivitis. Moreover, sex stratification demonstrated that effects relative to asthma and atopic sensitisation were confined essentially to males, whereas the observed risk association for rhinoconjunctivitis appeared stronger in females.

\section{Correlation between vitamin D and immunological variables at age 14 yrs}

Additional immunological biomarkers were measured at age 14 yrs as previously described [24], including levels of circulating granulocytes, and PBMC cytokine responses to adaptive and innate immune stimuli. Table 6 shows the results of Spearman correlation analyses comparing vitamin D levels with cytokine responses and peripheral granulocytes at age 14 yrs. Vitamin D at age $14 \mathrm{yrs}$ showed a significant positive correlation with HDM-induced IL-10 and interferon (IFN)- $\gamma$ measured from PBMC cultures, but not with T-helper cell (Th) type-2 cytokines. Vitamin D was also significantly positively correlated with levels of IL-10 and tumour necrosis factor (TNF) produced in response to innate stimuli at age 14 yrs. In contrast, vitamin D showed an inverse correlation with numbers of circulating eosinophils, basophils and neutrophils.

\section{DISCUSSION}

The major strength of this study is its prospective nature, integrating data on vitamin $\mathrm{D}$ levels in children at two different ages in conjunction with concurrent clinical and immunological phenotypes. Furthermore, as 693 of the children were studied at both time-points, vitamin D levels in the sera of children at aged 6 yrs were tested as a predictor of atopy and the developing clinical indicators of asthma at 14 yrs of age. This was a community cohort of children; there was no selection of highly atopic mothers [27] or children with pre-diagnosed asthma $[5,19,20]$. Without selection for asthmatic children in the study population, this study was more sensitive to any links between vitamin D levels, and signs and symptoms of the developing allergy and asthma signatures. In previous studies, the authors have shown that BHR is a major risk factor for asthma and high $\mathrm{IgE}$ levels to perennial allergens are a risk factor for BHR in the 14-yr age group [24].

Perth, at latitude $32^{\circ} \mathrm{S}$, has a typical Mediterranean climate. Despite the Australian outdoor lifestyle, only $41.4 \%$ of children

TABLE 4 Linear regression between vitamin $\mathrm{D}$ and continuous respiratory and allergic measures at age 6 yrs

\begin{tabular}{|c|c|c|c|c|c|c|c|c|c|c|c|c|}
\hline \multirow{2}{*}{$\begin{array}{l}\text { Variable at } \\
\text { age } 6 \text { yrs }\end{array}$} & \multicolumn{4}{|c|}{ Whole population } & \multicolumn{4}{|c|}{ Males } & \multicolumn{4}{|c|}{ Females } \\
\hline & Subjects & $\beta \pm S E$ & $\mathbf{t}$ & $\mathrm{p}$-value & Subjects & $\beta \pm S E$ & $t$ & $p$-value & Subjects & $\beta \pm \mathrm{SE}$ & $\mathbf{t}$ & p-value \\
\hline HDM IgE & 989 & $-0.063 \pm 0.004$ & -1.97 & 0.049 & 554 & $-0.088 \pm 0.004$ & -2.08 & 0.038 & 435 & $-0.045 \pm 0.006$ & -0.93 & 0.351 \\
\hline Food mix IgE & 989 & $-0.001 \pm 0.006$ & -0.02 & 0.980 & 554 & $-0.006 \pm 0.008$ & -0.14 & 0.886 & 435 & $0.000 \pm 0.009$ & 0.00 & 0.996 \\
\hline Phadiatop IgE & 988 & $-0.068 \pm 0.006$ & -2.15 & 0.032 & 554 & $-0.098 \pm 0.008$ & -2.31 & 0.021 & 434 & $-0.043 \pm 0.010$ & -0.89 & 0.373 \\
\hline
\end{tabular}

All variables were $\log _{10}$-transformed. Vitamin $\mathrm{D}$ was measured in $\mathrm{nmol} \cdot \mathrm{L}^{-1}$ and immunoglobulin $(\mathrm{lg}) \mathrm{E}$ was measured in kilounits per litre. $\beta$ : standardised correlation coefficient; t: $\beta$ divided by SE; HDM: house dust mite. 


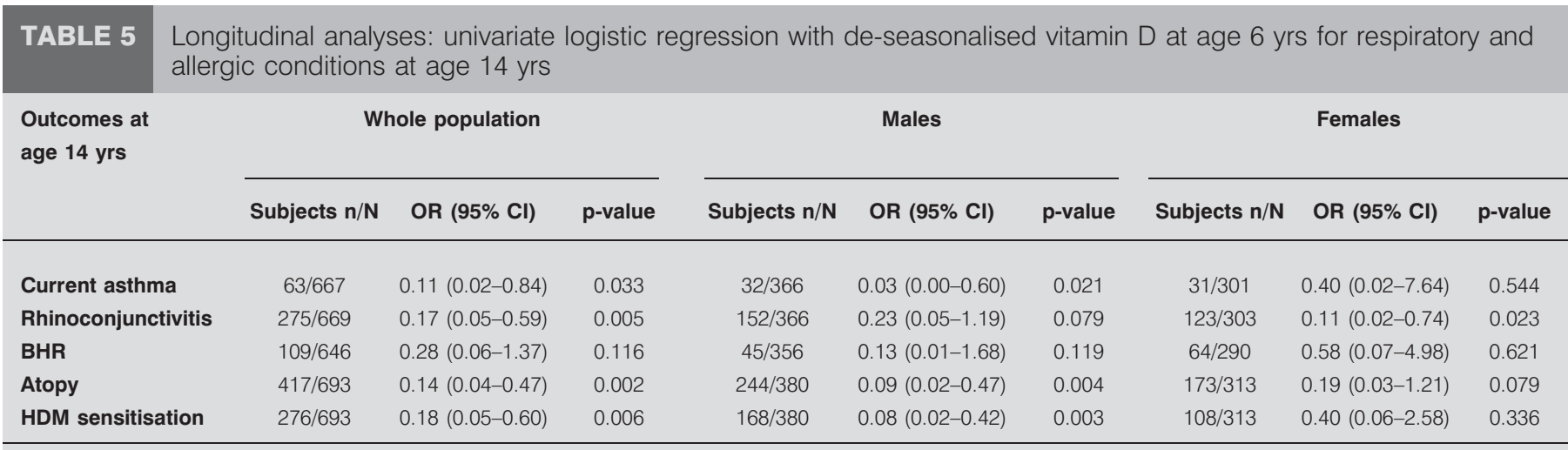

De-seasonalised vitamin D at age 6 yrs was calculated using a sinusoidal model, $\log _{10}$-transformed and included in logistic regression analyses for outcomes at age $14 \mathrm{yrs}$. $\mathrm{n}$ : total subjects in regression; $\mathrm{N}$ : subjects in regression with outcome; BHR: bronchial hyperresponsiveness; HDM: house dust mite.

at age $14 \mathrm{yrs}$ were vitamin D sufficient $\left(>75 \mathrm{nmol} \cdot \mathrm{L}^{-1}\right)$ during the Winter months of June-August. During Winter, $49.2 \%$ had insufficient vitamin D levels $\left(50-75 \mathrm{nmol} \cdot \mathrm{L}^{-1}\right)$ and $9.4 \%$ were deficient $\left(<50 \mathrm{nmol} \cdot \mathrm{L}^{-1}\right)$. The prevalence of vitamin $\mathrm{D}$ insufficiency in children is an international problem, with similar rates reported for US asthmatic children [5, 21]. Even in equatorial Costa Rica, $24.6 \%$ and $3.4 \%$ of children were found to be vitamin $\mathrm{D}$ insufficient and deficient, respectively [19]. The majority of subjects studied were classified into the same vitamin D status categories at ages 6 and 14 yrs (online supplementary table E8). While we have applied the cut-offs most commonly published

\begin{tabular}{|c|c|c|c|c|}
\hline \multirow{2}{*}{$\begin{array}{l}\text { TABLE } 6 \\
\text { Variable }\end{array}$} & \multicolumn{4}{|c|}{$\begin{array}{l}\text { Spearman's correlation of vitamin } D \text { at age } 14 \mathrm{yrs} \\
\text { with immunological variables collected at the } \\
\text { same age }\end{array}$} \\
\hline & & Subjects & $\mathbf{r}$ & $\mathrm{p}$-value \\
\hline \multicolumn{5}{|c|}{ Adaptive immunity } \\
\hline \multicolumn{5}{|c|}{ T-cell responses } \\
\hline \multicolumn{2}{|c|}{ HDM-induced IL-4 } & 1342 & -0.011 & 0.693 \\
\hline \multicolumn{2}{|c|}{ HDM-induced IL-5 } & 1374 & -0.007 & 0.810 \\
\hline \multicolumn{2}{|c|}{ HDM-induced IL-9 } & 1342 & -0.018 & 0.503 \\
\hline \multicolumn{2}{|c|}{ HDM-induced IL-10 } & 1374 & 0.062 & 0.022 \\
\hline \multicolumn{2}{|c|}{ HDM-induced IL-13 } & 1374 & 0.007 & 0.804 \\
\hline \multicolumn{2}{|c|}{ HDM-induced IFN- $\gamma$} & 1374 & 0.054 & 0.045 \\
\hline \multicolumn{5}{|c|}{ Innate immunity } \\
\hline \multicolumn{5}{|c|}{ TLR responses } \\
\hline \multicolumn{2}{|c|}{ LPS-induced IL-10 } & 1368 & 0.071 & 0.009 \\
\hline \multicolumn{2}{|c|}{ LPS-induced TNF } & 1368 & -0.069 & 0.011 \\
\hline \multicolumn{2}{|c|}{ Poly(I:C)-induced IL-10 } & 1367 & 0.072 & 0.007 \\
\hline \multicolumn{2}{|c|}{ Poly(l:C)-induced TNF } & 1367 & -0.097 & $<0.001$ \\
\hline \multicolumn{5}{|c|}{ Baseline granulocytes } \\
\hline \multicolumn{2}{|c|}{ Eosinophils } & 1377 & -0.054 & 0.045 \\
\hline \multicolumn{2}{|c|}{ Neutrophils } & 1377 & -0.084 & 0.002 \\
\hline \multicolumn{2}{|c|}{ Basophils } & 1377 & -0.084 & 0.002 \\
\hline
\end{tabular}

HDM: house dust mite; IL: interleukin; IFN: interferon; TLR: Toll-like receptor; LPS: lipopolysaccharide; TNF: tumour necrosis factor; poly(l:C): polyinosinic: polycytidylic acid. for classification of vitamin D status, this issue is controversial and it has been suggested that current cut-offs may greatly underestimate the levels vitamin $D$ required for optimal function of vitamin D-related processes [28, 29]. For this reason, we used continuous measures in all regression analyses for clinical outcomes.

At age 14 yrs, the strongest relationship between vitamin D and clinical phenotypes observed was for atopy, as exemplified by HDM sensitisation, followed by BHR, an important risk factor for asthma development [24]. The inverse correlations were mainly amongst males and it is noteworthy that the probability of atopy and HDM sensitisation was also greater in the male subjects (fig. 2) [24]. This contrasts with the significantly stronger immunomodulatory effects of vitamin D previously reported in adult females compared with males, including a stronger relationship between serum vitamin $\mathrm{D}$ and the activity of IL-10-secreting regulatory T-cells [30]. A functional synergy has been proposed between 1,25-dihydroxyvitamin D3 and 17- $\beta$-oestradiol, mediated through oestrogen receptor $\alpha$, to cause effects on vitamin D receptor expression, vitamin D3-inactivating enzyme (CYP24A1) and vitamin D3binding protein $[30,31]$, and this may make females more resilient against limiting 25-hydroxyvitamin D. With further sexual maturation and ageing of subjects in this longitudinal study, it will be interesting to see in future follow-ups if this correlation in the males persists, and/or whether the links between vitamin D levels, and asthma and allergy susceptibility in females increase over time. It is notable that the stronger inverse correlation between vitamin D levels and atopy and allergy phenotypes in the males was seen at both 6 and $14 \mathrm{yrs}$ of age, when sex hormone concentrations would have varied enormously. The possibility that the atopy phenotypes were sensitive to and controlled by lower levels of vitamin $\mathrm{D}$ in the females was considered; however, further supportive data are required. It is possible that our study lacked sufficient power to detect some associations between and clinical outcomes after stratifying the population by sex.

For children studied at $14 \mathrm{yrs}$, vitamin D levels were also compared with the responses of PBMCs exposed to innate stimuli and HDM allergen. Analysis of the HDM responses suggested that although the production of the Th2 cytokines 
did not fluctuate with vitamin D levels, cytokines produced by human regulatory cells (notably the combination of IL-10 and IFN- $\gamma$ [32]) were significantly and positively correlated. Many laboratories have shown that dendritic cell function can be modulated by vitamin $\mathrm{D}$ in vitro and more recently, this has been shown in vivo [13, 33]. Both induction [10, 34] and activation of regulatory T-cells [12] by 1,25-dihydroxyvitamin D3 have been reported and may explain the correlations observed, possibly indirectly via effects on dendritic cells. The profile of PBMC responses to the TLR4 and TLR3 ligands LPS and poly(I:C), respectively, suggest that in subjects with increased vitamin $\mathrm{D}$ levels, there was reduced production of pro-inflammatory TNF, which was balanced by increased production of the regulatory cytokine IL-10. This pattern accords with the predicted homeostatic control by 1,25dihydroxyvitamin D3 of the functions of myeloid cells (reviewed in [2]), which include both dendritic cell and macrophage populations within PBMCs. Mechanistically, the vitamin D receptor/1,25-dihydroxyvitamin D3 complex dosedependently interferes with the signalling of transcription factors, which may include the nuclear factor- $\mathrm{B}$-driven maturation pathway in macrophages and dendritic cells [35]. These data thus suggest that vitamin D "sufficiency" supports myeloid cell differentiation along the less inflammatory M2 pathway, which is characterised by increased production of IL10 and decreased production of TNF (reviewed in [36]). Ligand binding to the vitamin $\mathrm{D}$ receptor has also been shown to enhance responses to endogenous cortisol by enhancing IL-10 production by PBMCs $[5,10]$ and this mechanism may also contribute to the observed variations in TLR-induced cytokine production.

Vitamin D levels have not associated with allergy markers in all previous studies of asthmatic children. In the Childhood Asthma Management Program (CAMP) study of North American asthmatic children [20], low vitamin D levels were associated retrospectively with increased odds of hospitalisation during the previous year, and prospectively with severe asthma exacerbations over the following 4 yrs but not HDM IgE and eosinophil counts. In the CAMP study, 13\% of children were of African-American descent [21], whereas our study cohort comprised $>95 \%$ Caucasians. In the previous studies of asthmatic children, the frequency of skin test reactivity to any allergen was approximately $80-90 \%$. However, as ours was a community-based study, this percentage was lower $(60 \%$ at age $14 \mathrm{yrs}$ and $54 \%$ at age 6 yrs). Our study did not find a positive correlation between vitamin $\mathrm{D}$ levels and spirometric measurements as reported previously [5]; this may reflect the low number of asthmatics studied and the nature of this community cohort.

A growing body of evidence suggests that vitamin D deficiency in utero can impact on development of the fetal lung [37] and immune system. We were unable to address this issue and it is possible that such developmental effects may have reduced the associations observed in this study between vitamin D levels and asthma development in childhood. Future studies with longitudinal birth cohorts are needed to determine how vitamin D status in early life and throughout childhood modifies risks of asthma, allergy and related conditions.

\section{SUPPORT STATEMENT}

This work was supported by the National Health and Medical Research Council of Australia and the Raine Medical Research Foundation of the University of Western Australia (Perth, WA, Australia). Reagents for antibody measurement were provided gratis by Phadia AB (Uppsala, Sweden).

\section{STATEMENT OF INTEREST}

A statement of interest for the study itself can be found at www.erj. ersjournals.com/site/misc/statements.xhtml

\section{ACKNOWLEDGEMENTS}

We acknowledge with thanks the skilled technical assistance of J. Tizard (Telethon Institute for Child Health Research, Centre for Child Health Research, University of Western Australia, Perth, WA, Australia), and the study families and members of the Raine Study team who took part in the study.

\section{REFERENCES}

1 Black PN, Scragg R. Relationship between serum 25-hydroxyvitamin D and pulmonary function in the third National Health and Nutrition Examination Survey. Chest 2005; 128: 3792-3798.

2 Bouillon R, Carmeliet G, Verlinden L, et al. Vitamin D and human health: lessons from vitamin D receptor null mice. Endocr Rev 2008; 29: 726-776.

3 Holick MF. Resurrection of vitamin D deficiency and rickets. J Clin Invest 2006; 116: 2062-2072.

4 Holick MF. Vitamin D deficiency. N Engl J Med 2007; 357: 266-281.

5 Searing DA, Zhang Y, Murphy JR, et al. Decreased serum vitamin $\mathrm{D}$ levels in children with asthma are associated with increased corticosteroid use. J Allergy Clin Immunol 2010; 125: 995-1000.

6 Searing DA, Leung DY. Vitamin D in atopic dermatitis, asthma and allergic diseases. Immunol Allergy Clin North Am 2010; 30: 397-409.

7 Weiss ST, Litonjua AA. Maternal diet vs lack of exposure to sunlight as the cause of the epidemic of asthma, allergies and other autoimmune diseases. Thorax 2007; 62: 746-748.

8 Sutherland ER, Goleva E, Jackson LP, et al. Vitamin D levels, lung function, and steroid response in adult asthma. Am J Respir Crit Care Med 2010; 181: 699-704.

9 Litonjua AA, Weiss ST. Is vitamin D deficiency to blame for the asthma epidemic? J Allergy Clin Immunol 2007; 120: 1031-1035.

10 Xystrakis E, Kusumakar S, Boswell S, et al. Reversing the defective induction of IL-10-secreting regulatory $\mathrm{T}$ cells in glucocorticoidresistant asthma patients. J Clin Invest 2006; 116: 146-155.

11 Gorman S, Judge MA, Hart PH. Topical 1,25-dihydroxyvitamin $\mathrm{D}(3)$ subverts the priming ability of draining lymph node dendritic cells. Immunology 2010; 131: 415-425.

12 Gorman S, Judge MA, Burchell JT, et al. 1,25-dihydroxyvitamin D3 enhances the ability of transferred CD4+ CD25+ cells to modulate T helper type 2-driven asthmatic responses. Immunology 2010; 130: 181-192.

13 Hawrylowicz C, Ryanna K. Asthma and allergy: the early beginnings. Nat Med 2010; 16: 274-275.

14 Gold DR, Bloomberg GR, Cruikshank WW, et al. Parental characteristics, somatic fetal growth, and season of birth influence innate and adaptive cord blood cytokine responses. J Allergy Clin Immunol 2009; 124: 1078-1087.

15 Camargo CA Jr, Rifas-Shiman SL, Litonjua AA, et al. Maternal intake of vitamin $\mathrm{D}$ during pregnancy and risk of recurrent wheeze in children at 3 y of age. Am J Clin Nutr 2007; 85: 788-795.

16 Devereux G, Litonjua AA, Turner SW, et al. Maternal vitamin D intake during pregnancy and early childhood wheezing. Am J Clin Nutr 2007; 85: 853-859. 
17 Gale CR, Robinson SM, Harvey NC, et al. Maternal vitamin D status during pregnancy and child outcomes. Eur J Clin Nutr 2008; 62: 68-77.

18 Hypponen E, Sovio U, Wjst M, et al. Infant vitamin D supplementation and allergic conditions in adulthood: northern Finland birth cohort 1966. Ann NY Acad Sci 2004; 1037: 84-95.

19 Brehm JM, Celedon JC, Soto-Quiros ME, et al. Serum vitamin D levels and markers of severity of childhood asthma in Costa Rica. Am J Respir Crit Care Med 2009; 179: 765-771.

20 Brehm JM, Schuemann B, Fuhlbrigge AL, et al. Serum vitamin D levels and severe asthma exacerbations in the Childhood Asthma Management Program study. J Allergy Clin Immunol 2010; 126: 52-58.

21 Newnham JP, Evans SF, Michael CA, et al. Effects of frequent ultrasound during pregnancy: a randomised controlled trial. Lancet 1993; 342: 887-891.

22 Lewis JG, Elder PA. Serum 25-OH vitamin D2 and D3 are stable under exaggerated conditions. Clin Chem 2008; 54: 1931-1932.

23 Maunsell Z, Wright DJ, Rainbow SJ. Routine isotope-dilution liquid chromatography-tandem mass spectrometry assay for simultaneous measurement of the 25-hydroxy metabolites of vitamins D2 and D3. Clin Chem 2005; 51: 1683-1690.

24 Hollams EM, Deverell M, Serralha M, et al. Elucidation of asthma phenotypes in atopic teenagers through parallel immunophenotypic and clinical profiling. J Allergy Clin Immunol 2009; 124: 463-470.

25 Joseph-Bowen J, de Klerk NH, Firth MJ, et al. Lung function, bronchial responsiveness, and asthma in a community cohort of 6year-old children. Am J Respir Crit Care Med 2004; 169: 850-854.

26 van der Mei IA, Ponsonby AL, Dwyer T, et al. Vitamin D levels in people with multiple sclerosis and community controls in Tasmania, Australia. J Neurol 2007; 254: 581-590.

27 Kusel MM, de Klerk NH, Holt PG, et al. Role of respiratory viruses in acute upper and lower respiratory tract illness in the first year of life: a birth cohort study. Pediatr Infect Dis J 2006; 25: 680-686.
28 Norman AW, Bouillon R, Whiting SJ, et al. 13th Workshop consensus for vitamin D nutritional guidelines. J Steroid Biochem Mol Biol 2007; 103: 204-205.

29 Hollis BW, Wagner CL, Drezner MK, et al. Circulating vitamin D3 and 25-hydroxyvitamin D in humans: an important tool to define adequate nutritional vitamin D status. J Steroid Biochem Mol Biol 2007; 103: 631-634.

30 Correale J, Ysrraelit MC, Gaitan MI. Gender differences in 1,25 dihydroxyvitamin D3 immunomodulatory effects in multiple sclerosis patients and healthy subjects. J Immunol 2010; 185: 4948-4958.

31 Nashold FE, Spach KM, Spanier JA, et al. Oestrogen controls vitamin D3-mediated resistance to experimental autoimmune encephalomyelitis by controlling vitamin D3 metabolism and receptor expression. J Immunol 2009; 183: 3672-3681.

32 Trinchieri G. Regulatory role of T cells producing both interferon $\gamma$ and interleukin 10 in persistent infection. J Exp Med 2001;194: F53-F57.

33 Enioutina EY, Bareyan D, Daynes RA. Vitamin D3-mediated alterations to myeloid dendritic cell trafficking in vivo expand the scope of their antigen presenting properties. Vaccine 2007; 25: 1236-1249.

34 Barrat FJ, Cua DJ, Boonstra A, et al. In vitro generation of interleukin 10-producing regulatory $\mathrm{CD}^{+} \mathrm{T}$ cells is induced by immunosuppressive drugs and inhibited by T helper type 1 (Th1)and Th2-inducing cytokines. J Exp Med 2002; 195: 603-616.

35 Dong X, Lutz W, Schroeder TM, et al. Regulation of relB in dendritic cells by means of modulated association of vitamin $\mathrm{D}$ receptor and histone deacetylase 3 with the promoter. Proc Natl Acad Sci USA 2005; 102: 16007-16012.

36 Mantovani A, Sica A, Locati M. Macrophage polarization comes of age. Immunity 2005; 23: 344-346.

37 Zosky GR, Berry LJ, Elliot JG, et al. Vitamin D deficiency causes deficits in lung function and alters lung structure. Am J Respir Crit Care Med 2011; 183: 1336-1343. 